\title{
Analysis and Countermeasures of Stuck Failure of SR Steering Gear of a Ship
}

\author{
Xingxing Han, Yongquan Wang, Cun $\mathrm{Hu}$, Xianming Su \\ China Satellite Maritime Tracking and Control Department, Wuxi, China
}

\begin{abstract}
This paper introduces the structure and working principle of SR type steering gear, describes an example of stuck failure of the steering gear. The author uses the exclusion method and the shallow to deep method to analyze the causes of the failure from five aspects, and finally locates the failure, and then proposes two aspects of steering gear management considerations.
\end{abstract}

\section{Introduction}

At present, most ships use the rudder as a device to maintain or change course. The rudder is installed vertically behind the propeller. The steering gear includes power equipment for turning the rudder, a steering mechanism, and components (such as a tiller and a rudder fan) that apply torque to the rudder stock. Strictly speaking, the steering gear refers to the power equipment that makes the rudder move (for example, the electro-hydraulic steering gear refers to the electric motor and the hydraulic pump and auxiliary equipment driven by it), but it is customary on the ship to refer to the entire steering gear simply as the steering gear. [1]

Steering gear, as the ship's course control equipment, plays a vital role in ensuring the safety of the ship's maritime navigation. Equipment inspectors should carry out equipment maintenance as required, strengthen onduty inspections, timely find and resolve faults, ensure the stable and reliable operation of steering gear, and ensure navigation safety.

\section{Basic composition and working principle}

\subsection{Basic composition of steering gear}

The steering gear of the ship is composed of rudder, remote control system and hydraulic system. The rudder mechanism uses a rotary vane type rudder mechanism. Its main features include the following three points: (1). Small footprint, light weight, easy installation; (2). No external lubrication, simple management, and there is no lateral thrust on the rudder stock when turning the rudder. No lateral thrust can reduce the wear of the rudder bearing; (3). There are many parts to be sealed inside, leakage is not easy to find, and it is more troublesome to replace the seal. [1]
Remote control system of steering gear refers to the system that controls the steering gear from the bridge. And the ship uses an automatic steering system. The automatic steering system commonly uses a fixed course autopilot. After the course is set, when the ship yaw due to wind, current or asymmetrical effects of the propeller, the remote control system can automatically determine the deviation of the ship's actual course from the set course based on the compass. Then the remote control system sends a corresponding remote signal to steer it and return the boat to the set course. $[2,3]$

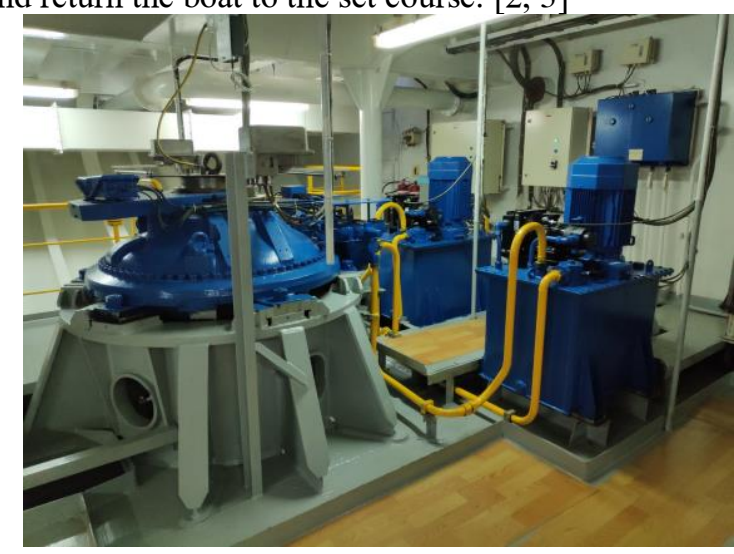

Fig. 1. Overview of steering gear hydraulic system

The hydraulic system of the ship's steering gear uses a ration oil pump as the main oil pump, and the electric remote control system is used to operate the electromagnetic directional valve to control the oil flow direction and the steering direction.

\subsection{Working principle of steering gear}

At present, almost all of the larger ships use electric hydraulic steering gear. Hydraulic steering gear uses the incompressibility of liquids and the controllability of flow rate and flow direction to achieve steering purposes. It is divided into two types: valve-controlled and pump-

\footnotetext{
* Corresponding author: hanhao663@163.com
} 
controlled. The ship's steering gear is a valve-controlled hydraulic steering gear.

The hydraulic pump of the valve-controlled steering gear uses a unidirectional fixed flow rate pump. When the steering gear is in operation, the pump runs continuously in the predetermined direction, and the suction, discharge direction and flow rate are unchanged. The direction of oil supply to the steering cylinder is controled by three-position four-way reversing valve. The command rudder angle signal given by the bridge is compared with the actual rudder angle signal from the rudder angle feedback transmitter connected to the rudder tiller (or rudder post). When the two deviate, the rudder angle signal is amplified. According to the different deviation direction, the solenoid coil on the corresponding side of the reversing valve is energized, so that the valve core deviates from the neutral position to one end, and supplies oil to the steering cylinder on one side, and the oil of the other cylinder is returned to the pump suction port through the reversing valve (Closed system). And then the rotor in the oil cylinder rotates, pushing the tiller and rudder blades to rotate. [4, 5]

When the actual rudder angle signal returned to the electrical control system by feedback transmitter is consistent with the commanded rudder angle signal, the solenoid coil of the reversing valve is de-energized, and the valve core returns to the neutral position, and the discharge oil of the pump is unloaded by the reversing valve. The oil path to the steering cylinder is closed, and the rudder blade stops at the commanded rudder angle.

When the instruction rudder angle deviation direction is opposite, the coil on the other side of the reversing valve is energized, and the direction in which the valve core deviates and the rudder direction are also reversed.

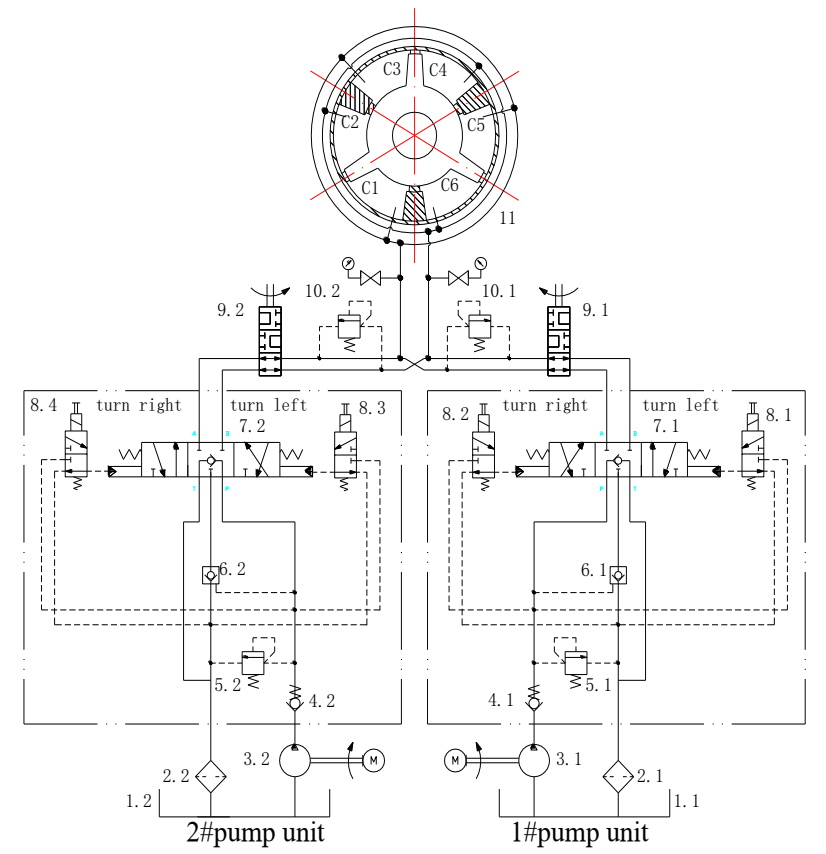

Fig. 2. Schematic diagram of steering gear hydraulic system.

\section{Failure phenomenon and cause analysis}

\subsection{Symptom description}

During a certain voyage of the ship, the right pump of the left steering gear continued to stuck, which prevented the right pump from being used normally, which seriously affected the ship's safe navigation at sea. The symptoms are as follows.

1. The stuck failure occurs when the right pump of the left steering gear is running in a single pump, and the stuck failure disappears when the left pump is running in a single pump, and the equipment is operating normally when the two pumps are running together.

2. In the remote control mode, the stuck failure occurs when the right pump of the left steering gear is running in a single pump, and there is also a stuck failure phenomenon in the local control mode.

3. In the remote control mode, the right pump of the left steering gear is running in a single pump. When the rudder is driven to the right, the equipment runs normally, and when the rudder is driven to the left, the stuck failure phenomenon occurs; the operating conditions are the same in the local control mode.

\subsection{Cause Analysis}

\subsubsection{No oil supplied from main pump}

If the main pump fails, for example, if it is damaged or prevented from rotating, it will not be able to supply oil properly, and the stuck failure will occur. The staff first locates the cause of the fault on the right unit of the left steering gear, and conducts a detailed inspection of the right pump of the left steering gear. It is found that the right pump can start normally and the oil pressure is normal after the start.

\subsubsection{Gas is mixed in the main oil circuit}

There is a lot of gas mixed in the main oil circuit, and even if the rudder is steered in the local control mode, the stuck failure will occur. The sources of air in the system may be: incomplete exhaust after filling or overhauling, or the working tank level is too low or the oil replenish pressure is too low, making the pump sucks air, or sucks air from the system leak or the cylinder seal. After deflating the system and checking that the oil level of the working oil tank is normal, but after the equipment has been running for a period of time, the stuck failure of the right pump of the left steering gear appears again.

\subsubsection{Main oil circuit blocked}

The main oil circuit is clogged, for example, the oil return filter of the main oil circuit is dirty, resulting in abnormal changes in oil pressure during steering, and stuck failure may also occur. We checked and replaced 
the oil return filter of the main oil circuit of the right pump of the left steering gear, and found that the oil pressure changed normally when steering, but the fault still existed.

\subsubsection{Remote control system failure}

If the remote control system of steering gear fails, the stuck failure will also occur. The insulation of the remote control system, the related contacts and the commutator were tested in detail. The current and voltage of the related equipment were tested by using professional tools. The results showed that the remote control system of the steering gear was normal and reliable. [6]

\subsubsection{Damaged combination valve}

The combination valve includes a pilot valve and a three-position four-way valve. If impurities are mixed in the hydraulic oil and the oil enters and exits for a long time, it will cause wear on the valve core and sealing gasket of the combination valve, and the valve core will not operate properly, or the pilot valve oil pressure in the control oil circuit cannot be established, all of which will cause stuck failure phenomenon. We inspected the threeposition four-way valve and found that there was a fine iron wire in the control oil circuit of the three-position four-way valve core. We removed it and cleaned the reversing valve. The fault disappeared briefly. [7]

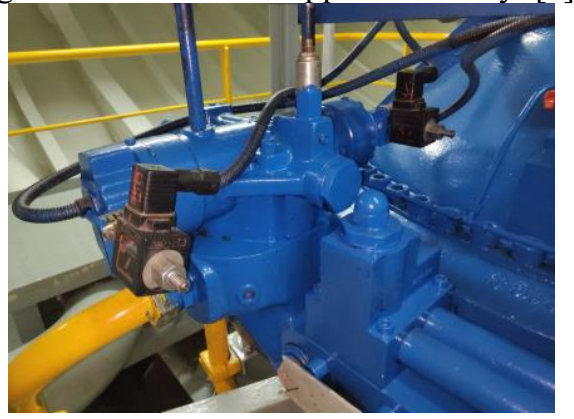

Fig. 3. Combination valve schematic

After the steering gear has been running for a while, the stuck failure phenomenon appears again. In view of the situation where the remote control steering condition is the same as the local control steering condition, we have disassembled and inspected the pilot valve that controls the rudder to the right. Because the pilot valve cannot be judged by naked eyes to determine whether it is damaged, in order to solve the problem as soon as possible, we renewed the pilot valve, and the steering gear was debugged again after the replacement, and the equipment was operating normally. As of October 2016, the steering gear of the ship has been in good working condition, and the stuck failure of right pump of the left steering gear has been eliminated.

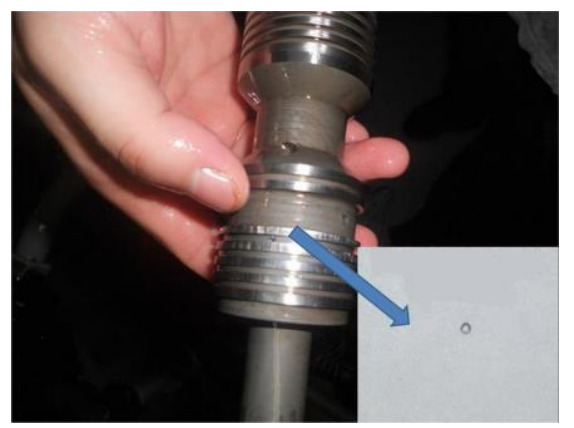

Fig. 4. A fine iron wire on the three-position four-way valve core

\subsection{Fault location}

After disassembling the replaced pilot valve, the possible causes of failure are analyzed as follows.

1. Pilot valve gasket was damaged

As a result of the pilot valve gasket was damaged, the seal was not tight. When the solenoid valve received the signal action, the oil pressure of the control oil circuit could not be established. Then the three-position fourway reversing valve did not operate or the action was not in place, so the stuck failure occured.

2. Impurities in hydraulic oil

The long-term use of this hydraulic oil caused severe wear of the valve core and the valve body of the pilot valve. When the solenoid valve received a command action, it was easy to cause the pilot valve core not to move in place, resulting in leakage of the control oil circuit and oil pressure could not be established. As a result, the three-position four-way reversing valve did not move in place, so the stuck failure occured.

\section{Points for attention in steering gear management}

In view of the above reason analysis, in order to avoid the similar fault of the steering gear and ensure the stable and reliable operation of the steering gear during the maritime mission, the following matters should be paid attention to in the steering gear management in the future.

\subsection{Strengthen duty inspections}

During the on-duty inspection, the on-duty personnel must focus on the following matters, and deal with in case of abnormality. The oil level in the working oil tank should be maintained at about $2 / 3$ of the display range of the oil level gauge. The most suitable oil temperature is $30-50^{\circ} \mathrm{C}$. In the main oil circuit, the oil pressure on the discharge side of the main pump should not be higher than the maximum working oil pressure as specified in the instruction manual, and the oil pressure on the suction side of the main pump should not be lower than the normal value determined by the oil replenishment condition (closed system) or oil suction condition (Open system). Pumps and motors should not have overheating, and the temperature of the bearing parts is generally 10 $20^{\circ} \mathrm{C}$ higher than the oil temperature. In use, check each 
air release valve, bypass valve and stop valve, and each fixing and connecting nut to prevent it from leaving the correct position or loosening due to vibration.

\subsection{Regular maintenance}

The SR type steering gear user manual clearly indicates the items and time intervals for equipment maintenance. We should strictly maintain the equipment in accordance with the requirements in the instructions. During operation, pay attention to the pressure difference between the front and back of the filter, and replace the filter element in time. Sliding surfaces such as the oil cylinder plunger should be kept clean, and an appropriate amount of working oil should be applied regularly.

In addition, when the situation requires, must measure the clearance of each abrasion part of the steering mechanism, calibrate and adjust the safety valve or other hydraulic control valves. Electrically, the insulation should be measured regularly, and the contacts and commutators should be inspected and cleaned to prevent the joints from loosening. $[8,9]$

\section{Conclusion}

As a ship's heading control equipment, the steering gear plays a vital role in ensuring the safety of the ship's maritime navigation. This article finds the crux of the problem by eliminating the problem of the stuck failure to a ship that has been a problem for a long time. The processing procedures and elimination methods have a good reference meaning for how to cope with similar failures of the same type of steering gear on other ships.

\section{References}

1. Q. Fei, Ship auxiliary machine. M. (2005)

2. Z.B. Shi, Turbine Maintenance and Repair. M. (2012)

3. X.L. Wang, L. Xu, X.X. Han, Machine Tool \& Hydraulics. J. 43, 22 (2015)

4. D.L. Cai, Navigation of China. J. 38, 4 (2015)

5. L. CHEN, T. LU, Ship Science and Technology. J. 36, 12 (2014)

6. X.X. Jiang, S.F. Lin, Ship Engineering. J. 30, 6 (2008)

7. R.S. Cui, Shanghai Shipbuilding. J. 2 (2007)

8. X.Q. Wu, China Water Transport. J. 8, 4 (2008)

9. Z.J. Huang, Z. Yuan, Practical technology for fault diagnosis and monitoring of hydraulic equipment. M. (2006) 